\title{
COMMUNICATION
}

Cite this: DOI: 10.1039/x0xx00000x

\section{Lanthanoid $\beta$-triketonates: a new class of highly efficient NIR emitters for bright NIR-OLEDs}

\author{
Brodie L. Reid, ${ }^{a, b}$ Stefano Stagni, ${ }^{c}$ Joanna M. Malicka, ${ }^{d}$ Massimo Cocchi, ${ }^{d, e}$ Garry S. \\ Hanan, ${ }^{b}$ Mark I. Ogden ${ }^{a, *}$ and Massimiliano Massi ${ }^{a,}$
}

Received 00th January 2012,

Accepted 00th January 2012

DOI: $10.1039 / \times 0 \times x 00000 x$

www.rsc.org/

\begin{abstract}
The reaction of hydrated $\mathrm{YbCl}_{3}$ with potassium tribenzoylmethanide yields new bimetallic tetranuclear $\mathrm{Yb}^{3+} / \mathrm{K}^{+}$assemblies. These species not only possess the longest excited state lifetime and quantum yield reported for the $\mathrm{Yb}$ diketonate family but are also suitable to be incorporated in NIR-OLEDs, whose performance outclasses any other reported lanthanoid-based device with NIR emission.
\end{abstract}

Research into luminescent species emitting in the visible spectrum and their use for the fabrication of organic light emitting devices (OLEDs), as a replacement for silicon-based technologies, has been extremely active in the past decades. ${ }^{1,2}$ More recently however, there has been growing interest in near-infrared (NIR) emission and associated NIR-OLEDs, as such devices find potential applications in a variety of relevant areas including telecommunication, optical signalling, night-vision devices, bioimaging and light-activated medical therapies. ${ }^{1,3-7}$ Some elements of the lanthanoid series have NIR emission and, in particular, the NIR luminescence from $\mathrm{Yb}^{3+}$ ions is studied due to its characteristic ${ }^{7} \mathrm{~F}_{5 / 2} \rightarrow{ }^{7} \mathrm{~F}_{7 / 2}$ line-like emission at 900-1100 nm. ${ }^{8,9}$ However, a drawback of many of the reported $\mathrm{Yb}^{3+}$ species is that their NIR emission is often efficiently quenched by the vibrational overtones of $\mathrm{CH}$ bonds within the sensitising ligands. ${ }^{3}$ This issue can be counteracted by the preparation of fully fluorinated or deuterated organic antennae ${ }^{3,10}$ or by excluding any high-energy vibrating bonds in close proximity to the $\mathrm{Yb}^{3+}$ centre. ${ }^{11,12}$ This strategy however, adds significant complexity to the preparation and optimisation of libraries of targeted sensitising ligands. In this context, $\beta$-diketonates have received much attention as readily accessible chelating O-donor ligands capable of forming stable lanthanoid complexes, which are also suitable to be incorporated in OLEDs. The species reported vary from mononuclear complexes to larger molecular oxo/hydroxo, carbonato, and halogen-bridging clusters. ${ }^{1,13-17} \beta$-Diketonate ligands modified to improve NIR emission have been well investigated. ${ }^{18-20}$

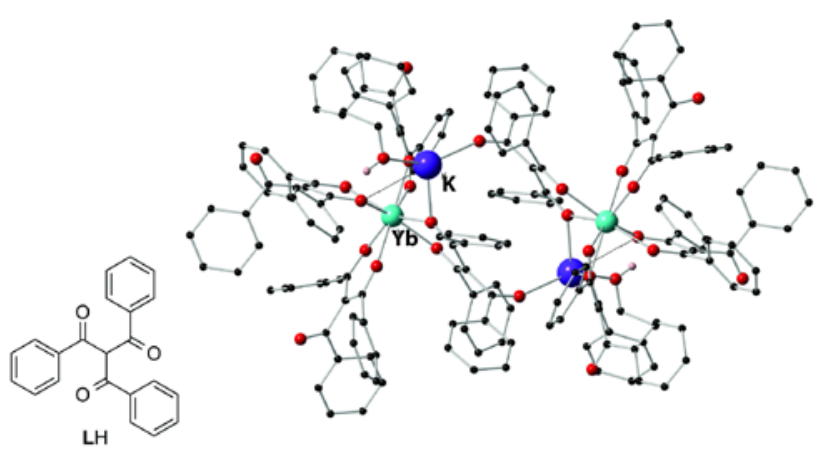

Figure 1. Ligand $\mathbf{L H}$ and X-ray crystal structure of $\left[\mathrm{Yb}(\mathrm{K} \cdot \mathrm{HOEt})(\mathrm{L})_{4}\right]_{2} . \mathrm{H}$ atoms, aside from ethanol $\mathrm{OH}$, are omitted for clarity.

In stark contrast, only three reports on lanthanoid complexes bearing $\beta$-triketonate ligands have appeared in the literature. 21-23 Furthermore, no structural characterisation of lanthanoid complexes bound to $\beta$-triketonate nor any investigation of sensitised NIR emission from their corresponding lanthanoid complexes has been reported. Indeed, a search of the $\mathrm{CSD}^{24}$ indicates that no metal complex of tribenzoylmethanide or triacetylmethanide has ever been structurally characterised, despite these ligands being a seemingly obvious extension of the classic $\beta$-diketonate motif.

The aim of this research was therefore to investigate the largely unexplored coordination and photophysical properties of lanthanoid $\beta$-triketonate complexes as well as their use in the fabrication of NIROLEDs. As a starting point, we focused on the complexation of $\mathrm{Yb}^{3+}$ cations with the tribenzoylmethane ligand (LH, Figure 1). Initial attempts to isolate the typical 3:1 ligand/metal mononuclear complex produced instead a bimetallic $2: 2 \mathrm{Yb}^{3+} / \mathrm{K}^{+}$assembly. This complex displayed a remarkably long excited state lifetime and 
relatively high quantum yield when compared to the parent $\beta$ diketonate complexes of $\mathrm{Yb}^{3+}$, despite the presence of multiple $\mathrm{CH}$ bonds within the ligands.

The tribenzoylmethane ligand LH (2-benzoyl-1,3-diphenyl-1,3propanedione) was prepared following a slightly modified procedure, ${ }^{25}$ in which dibenzoylmethane was reacted with benzoyl chloride and $\mathrm{NaH}$ in diethyl ether. The reaction of $\mathrm{LH}$ with hydrated $\mathrm{YbCl}_{3}$ in the presence of $\mathrm{KOH}$ in ethanol resulted in the formation of the complex $\left[\mathrm{Yb}(\mathrm{K} \cdot \mathrm{HOEt})(\mathrm{L})_{4}\right]_{2}$ (Figure 1). The synthesis of this bimetallic tetranuclear assembly was then stoichiometrically rationalised such that a mixture of hydrated $\mathrm{YbCl}_{3}$ and four equivalents of both $\mathrm{LH}$ and $\mathrm{KOH}$ were made to react in refluxing ethanol, giving an appreciable yield of $\sim 15 \%$ of the bimetallic complex.

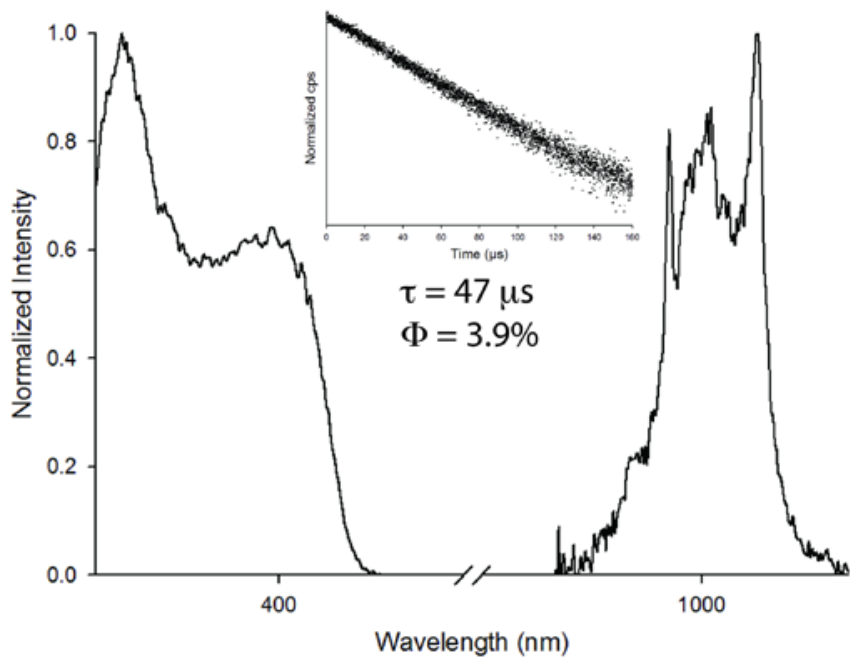

Figure 2. Excitation and emission spectra of $\left[\mathrm{Yb}(\mathrm{K} \cdot \mathrm{HOEt})(\mathrm{L})_{4}\right]_{2}$. The emission spectrum was recorded upon excitation at $\lambda_{\text {ex }}=350 \mathrm{~nm}$. Inset: excited state decay measured by monitoring the emission at $\lambda_{e m}=1,035 \mathrm{~nm}$.

$\left[\mathrm{Yb}(\mathrm{K} \cdot \mathrm{HOEt})(\mathbf{L})_{4}\right]_{2}$ crystallised as a triclinic structure and comprises of an overall neutral species where the combined $8+$ charges of two $\mathrm{Yb}^{3+}$ and two $\mathrm{K}^{+}$cations are counterbalanced by the presence of eight deprotonated anionic ligands. The complex can be viewed as a dimer disposed about a centre of symmetry. The eight-coordinate $\mathrm{Yb}^{3+}$ cation adopts a geometry best described as a square antiprismatic or distorted C4 symmetry, bound to four ligands in the bidentate mode typical of diketonate complexes. The third keto-O atoms on three of these ligands are not involved in any close contacts, while the fourth bridges to form the dimer, linking to a centrosymmetrically related $\mathrm{K}^{+}$ion. The remainder of the coordination sphere of the $\mathrm{K}^{+}$cation comprises of two $\mu-\mathrm{O}$ atoms bridging to the $\mathrm{Yb}^{3+}$ cation and an ethanol $\mathrm{O}$ atom. The $\mathrm{Yb} \cdots \mathrm{Yb}$ distance was found to be $8.90 \AA$ and it is therefore expected that $\mathrm{Yb}$ $\mathrm{Yb}$ energy transfer processes are not likely to occur. ${ }^{26}$

The lowest singlet $\left({ }^{1} \pi \pi^{*}\right)$ and triplet $\left({ }^{3} \pi \pi^{*}\right)$ excited state energies of the ligand $\left(\mathbf{L}^{-}\right)$were determined from the corresponding $\mathrm{Gd}^{3+}$ complex in a frozen ethanol matrix at $77 \mathrm{~K}$ and were found to lie at $25,575 \mathrm{~cm}^{-1}$ and $20,704 \mathrm{~cm}^{-1}$, respectively (see ESI, Figure S5). ${ }^{23}$ The energy difference between the ligand ${ }^{3} \pi \pi^{*}$ state and the lowest $\mathrm{Yb}^{3+}$ excited state ${ }^{7} \mathrm{~F}_{5 / 2}$ is $10,454 \mathrm{~cm}^{-1}$. According to previously reported investigations, this value should favour an efficient sensitisation., ${ }^{3,27}$ However, energy transfer to a higher-energy charge transfer state of $\mathrm{Yb}^{2+}$ could also be invoked, which usually requires the energy of the ${ }^{3} \pi \pi^{*}$ state to be above $19,000 \mathrm{~cm}^{-1} .26,28$

While measurements in solution suggested that the structure might not maintained upon dissolution (see ESI, Figures S6-7), in the solid state $\left[\mathrm{Yb}(\mathrm{K} \cdot \mathrm{HOEt})(\mathrm{L})_{4}\right]_{2}$ displays characteristic $\mathrm{Yb}^{3+}$ centred NIR emission (Figure 2 ) upon excitation in the UV region down to visible light above $400 \mathrm{~nm}$. The emission originates as a consequence of the antenna effect from the $\mathbf{L}^{-}$ligands, as suggested by the similarity between the excitation (Figure 2) and absorption spectra (see ESI, Figure S4) of the complex and ligand, respectively. The observed luminescence is attributed to the ${ }^{7} \mathrm{~F}_{5 / 2} \rightarrow{ }^{7} \mathrm{~F}_{7 / 2}$ transition of $\mathrm{Yb}^{3+}$, which is split into four main bands due to crystal-field effects. ${ }^{29,30}$ The absence of ligand-centred phosphorescence and direct excitation of $\mathrm{Yb}^{3+}$ in the emission and excitation spectra, respectively, provides evidence of an efficient energy transfer from the sensitising triketonate ligand.

The observed lifetime decay $\left(\tau_{\text {obs }}\right)$ of $\left[\mathrm{Yb}(\mathrm{K} \cdot \mathrm{HOEt})(\mathbf{L})_{4}\right]_{2}$ in the solid state at room temperature is satisfactorily fitted by a monoexponential function (Figure 2, inset), which is indicative of one unique NIR emitting species in the complex in agreement with the presence of an inversion centre. The $\tau_{\text {obs }}$ value is $47 \mu$ s and, to the best of our knowledge, this excited state decay is remarkably longer than any reported $\mathrm{Yb}^{3+}$ complex, in the solid state, belonging to the family of $\beta$-diketonate ligands, even where multiphonon relaxation is reduced by the lack of $\mathrm{CH}$ bonds. In fact, the highest lifetime reported for $\mathrm{Yb}^{3+}$ with perfluorinated $\beta$-diketonate ligands in the solid state is $12 \mu \mathrm{s}^{20}$

In comparison, the complex $\left[\mathrm{Yb}(\mathrm{K} \cdot \mathrm{HOEt})(\mathrm{L})_{4}\right]_{2}$ reported herein utilises a relatively simple ligand possessing $\mathrm{CH}$ bonds closer to the $\mathrm{Yb}^{3+}$ with a lifetime decay comparable to the above-mentioned examples. The overall quantum yield $\left(\Phi^{\llcorner}{ }_{L n}\right)$ and quantum efficiency $\left(\Phi^{L n}{ }_{L n}\right)$ for both complexes were estimated assuming $100 \%$ sensitisation efficiency $\left(\eta_{\text {sens }}\right)$ and radiative lifetime $\left(\tau_{R}\right)$ for $\mathrm{Yb}^{3+}$ of $1.2 \mathrm{~ms}$, as it has been done for analogous $\mathrm{Yb}^{3+}$ diketonate species. ${ }^{30,31}$ Under these assumptions, the quantum efficiency (and hence overall quantum yield) is 3.9\%. This value is amongst the highest reported for $\mathrm{Yb}^{3+}$ complexes in the solid state; the most comparable values are those reported with experimentally calculated values of radiative lifetime $\left(\tau_{R}\right)$, which are usually faster than the assumed $\tau_{\mathrm{R}}=1.2 \mathrm{~ms}{ }^{26}$ If we assumed an $\tau_{\mathrm{R}}<$ $1.2 \mathrm{~ms}$, the value of $\Phi_{\mathrm{Ln}}^{\mathrm{L}}$ would increase even further. The investigation into an accurate measurement of the quantum efficiency and quantum yield is currently underway.
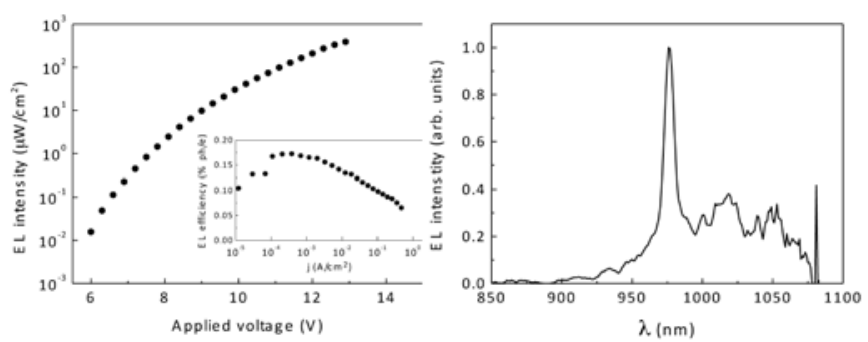
Figure 3. Left: NIR electroluminescence intensity versus applied voltage of the OLED; inset: NIR external efficiency versus current density. Right: Electroluminescence spectrum of OLED.

The complex $\left[\mathrm{Yb}(\mathrm{K} \cdot \mathrm{HOEt})(\mathbf{L})_{4}\right]_{2}$ was further assessed as an emissive species for the fabrication of NIR-OLEDs. The devices were fabricated by sublimation on glass substrates pre-coated with indium tin oxide (ITO), semitransparent to the light generated in the emitting layer (EML). The composition of the OLED was as follows: i) ITO anode; ii) 1,3-bis(N-carbazolyl)benzene (mCP, $60 \mathrm{~nm})$; iii) EML $\left[\mathrm{Yb}(\mathrm{K} \cdot \mathrm{HOEt})(\mathrm{L})_{4}\right]_{2}$ and $\mathrm{mCP}$ in a $1: 1$ mass ratio $(30 \mathrm{~nm})$; iv) 1,3,5-tris(N-phenylbenzimidazol-2-yl)benzene (TPBi, $25 \mathrm{~nm}) ; \mathrm{v}) \mathrm{LiF} / \mathrm{Al}$ cathode $(0.5 \mathrm{~nm}$ of $\mathrm{LiF}, 100 \mathrm{~nm}$ of Al).

Figure 3 shows the plots of electroluminescence (EL) intensity versus voltage and external efficiency versus current density of the studied device. The external quantum efficiency reaches $0.17 \% \mathrm{ph} / \mathrm{e}$ and the maximum EL intensity is $390 \mu \mathrm{W} / \mathrm{cm}^{2}$ at $12.9 \mathrm{~V}$, which originates exclusively from the $\mathrm{Yb}^{3+}$-centred NIR emission peaked at $976 \mathrm{~nm}$. To the best of our knowledge, the performance of this device is better than any other NIR-OLED previously reported where lanthanide complexes were used as emissive species in the composition of the EML. ${ }^{14,32-34}$

\section{Conclusions}

In conclusion, we have reported the synthesis of a novel neutral tetranuclear bimetallic $\mathrm{Yb}^{3+} / \mathrm{K}^{+}$assembly, by combination of $\mathrm{Yb}^{3+}$ with a triketonate sensitiser in the presence of potassium hydroxide. The $\mathrm{Yb}^{3+}$ ion in each complex is devoid of directly coordinated solvent and displays characteristic $\mathrm{Yb}^{3+}$-centred emission in the solid state. The emission has a long lived lifetime previously unseen in $\mathrm{Yb}^{3+}$ complexes bearing analogous diketonate ligands in the solid state, even where the ligand was perfluorinated to minimise quenching. A highly efficient NIR-OLED using $\left[\mathrm{Yb}(\mathrm{K} \cdot \mathrm{HOEt})(\mathrm{L})_{4}\right]_{2}$ as the source of the emitting layer was fabricated, demonstrating that this species is a suitable precursor in optical materials science. The performance of the device showed significant improvement compared to OLEDs based on NIR emitting lanthanide complexes reported to date, highlighting how the exceptional photophysical properties of the complex can be readily transferred to the device.

\section{Notes and references}

${ }^{a}$ Department of Chemistry, Curtin University, Kent Street, Bentley 6102 WA, Australia.

${ }^{b}$ Department of Chemistry, D-600 Université de Montréal, 2900 Edouard-Montpetit Montréal, Quebec, Canada.

${ }^{c}$ Department of Industrial Chemistry “Toso Montanari”, University of Bologna, Viale Risorgimento 4, 40129 Bologna, Italy.

${ }^{d}$ Laboratory of Micro and Submicro Enabling Technologies of EmiliaRomagna Region S.c.r.l. (MIST E-R S.c.r.l.), via Gobetti 101, 40129 Bologna, Italy.

${ }^{e}$ Institute for Organic Synthesis and Photoreactivity, CNR, via Gobetti 101, 40129 Bologna.

Electronic Supplementary Information (ESI) available: Synthetic details for $\mathbf{L H}$ and $\left[\mathrm{Yb}(\mathrm{K} \cdot \mathrm{HOEt})(\mathbf{L})_{4}\right]_{2}$; complete NMR details for $\mathbf{L H}$; X-ray crystallographic data for $\left[\mathrm{Yb}(\mathrm{K} \cdot \mathrm{HOEt})(\mathbf{L})_{4}\right]_{2}$ (CCDC 1001908); details for the photophysical measurements, OLED fabrication and OLED characterisation. See DOI: 10.1039/b000000x/. M.M. wishes to thank the ARC for funding. B.L.R. wishes to thank Curtin University for the APA and the University of Montreal. G.S.H. thanks the Natural Sciences and Engineering Research Council of Canada. J.M.M and M.C. thank Consorzio MIST E-R.

1. $\quad$ A. De Bettencourt-Dias, Dalton Trans., 2007, 2229-2241.

2. H. Yersin, A. F. Rausch, R. Czerwieniec, T. Hofbeck, and T. Fischer, Coord. Chem. Rev., 2011, 255, 2622-2652. J. C. G. Bünzli and S. V. Eliseeva, 8.08 Photophysics of Lanthanoid Coordination Compounds, Elsevier Ltd., 2013.

4. S. V. Eliseeva and J.-C. G. Bünzli, New J. Chem., 2011, 35, 11651176.

J. Bünzli, Chem. Rev., 2010, 110, 2729-2755.

S. Eliseeva and J. Bünzli, Chem. Soc. Rev., 2009, 39, 189-227.

A. De Bettencourt-Dias, P. S. Barber, and S. Bauer, J. Am. Chem. Soc., 2012, 134, 6987-6994.

A. Beeby, R. S. Dickins, S. Faulkner, D. Parker, and J. A. Gareth Williams, Chem. Commun., 1997, 1401-1402.

9. M. Albrecht, O. Osetska, R. Fröhlich, J.-C. G. Bünzli, A. Aebischer, F. Gumy, and J. Hamacek, J. Am. Chem. Soc., 2007, 129, 14178-14179.

10. P. B. Glover, A. P. Bassett, P. Nockemann, B. M. Kariuki, R. Van Deun, and Z. Pikramenou, Chem. Eur. J., 2007, 13, 6308-6320.

11. E. R. Trivedi, S. V. Eliseeva, J. Jankolovits, M. M. Olmstead, S. Petoud, and V. L. Pecoraro, J. Am. Chem. Soc., 2014, 136, 15261534.

12. A. P. Bassett, R. Van Deun, P. Nockemann, P. B. Glover, B. M. Kariuki, K. Van Hecke, L. Van Meervelt, and Z. Pikramenou, Inorg. Chem., 2005, 44, 6140-6142.

13. P. C. Andrews, W. J. Gee, P. C. Junk, and M. Massi, New J. Chem., 2013, 37, 35-48

14. T. S. Kang, B. S. Harrison, M. Bouguettaya, T. J. Foley, J. M. Boncella, K. S. Schanze, and J. R. Reynolds, Adv. Funct. Mater., 2003, 13, 205-210.

$15 . \quad$ L. S. Natrajan, A. J. Blake, C. Wilson, J. A. Weinstein, and P. L. Arnold, Dalton Trans., 2006, 4465-4473.

16. L.-N. Sun, H.-J. Zhang, Q.-G. Meng, F.-Y. Liu, L.-S. Fu, C.-Y. Peng, J.-B. Yu, G.-L. Zheng, and S.-B. Wang, J. Phys. Chem. B, 2005, 109, 6174-6182.

17. X. Guo, H. Guo, L. Fu, L. D. Carlos, R. A. S. Ferreira, L. Sun, R. Deng, and H. Zhang, J. Phys. Chem. C, 2009, 113, 12538-12545.

18. J.-H. Kim and Y.-P. Park, J. Kor. Phys. Soc., 2003, 43, 277-281.

19. P. Martín-Ramos, P. S. Pereira da Silva, V. Lavín, I. R. Martín, F. Lahoz, P. Chamorro-Posada, M. Ramos Silva, and J. Martín-Gil, Dalton Trans., 2013, 42, 13516-13526.

20. S. Biju, Y. K. Eom, J.-C. G. Bünzli, and H. K. Kim, J. Mater. Chem. C, 2013, 1, 6935.

21. M. Ismail, S. J. Lyle, and J. E. Newbery, J. Inorg. Nucl. Chem., 1969, 31, 2091-2093.

22. G. A. Crosby and R. E. Whan, J. Chem. Phys., 1960, 32, 614-615.

23. G. A. Crosby, R. E. Whan, and R. M. Alire, J. Chem. Phys., 1961, 34, 743-748.

24. F. H. Allen, Acta Cryst. B, 2002, 58, 1-9.

$25 . \quad$ J. L. Guthrie and N. Rabjohn, J. Org. Chem., 1957, 22, 176-178.

26. N. M. Shavaleev, R. Scopelliti, F. Gumy, and J.-C. G. Bünzli, Inorg. Chem., 2009, 48, 7937-7946.

27. M. Mehlstäubl, G. S. Kottas, S. Colella, and L. De Cola, Dalton Trans., 2008, 2385-2388.

$28 . \quad$ W. D. Horrocks, J. P. Bolender, W. D. Smith, and R. M. Supkowski, J. Am. Chem. Soc., 1997, 119, 5972-5973.

29. N. M. Shavaleev, R. Scopelliti, F. Gumy, and J.-C. G. Bünzli, Inorg. Chem., 2009, 48, 6178-6191.

30. N. M. Shavaleev, R. Scopelliti, F. Gumy, and J.-C. G. Bünzli, Inorg. Chem., 2009, 48, 2908-2918.

31. M. H. V. Werts, R. T. F. Jukes, and J. W. Verhoeven, Phys. Chem. Chem. Phys., 2002, 4, 1542-1548.

32. M. A. Katkova, A. P. Pushkarev, T. V. Balashova, A. N. Konev, G. K. Fukin, S. Y. Ketkov, and M. N. Bochkarev, J. Mater. Chem., 2011, 21, 16611-16620.

33. E. V. Baranov, G. K. Fukin, T. V. Balashova, A. P. Pushkarev, I. D. Grishin, and M. N. Bochkarev, Dalton Trans., 2013, 42, 15699- 
15705.

34. H. Wei, G. Yu, Z. Zhao, Z. Liu, Z. Bian, and C. Huang, Dalton Trans., 2013, 42, 8951-8960. 